\title{
Application Research on International Trade Information Management System Oriented On Service
}

\author{
YIN Kejia ${ }^{1, a}$ \\ ${ }^{1}$ Jiangxi college of foreign study, NanChang 330099, China \\ a ykj1214@163.com
}

Keywords: International trade, Information Management System, Service

\begin{abstract}
With the rapid development of network communication technology and Internet technology, international trade enterprises will face the business operation mode change by using the advanced information technology to strengthen the traditional advantages itself. The application of international trade information management system shows obvious advantages on the establishment of risk control system, strengthening with the international business communication between information platform, decreasing the cost of manufacturing and logistics, reducing the cost of customs clearance as well as improving customs clearance efficiency. Web has been more and more popular; Web with its abundant information resources and convenient way to browse makes people feel the benefits of information sharing.
\end{abstract}

\section{Design of international trade information management system based on B/S mode}

The general introduction of the international trade information management system

The international trade information management system based on B/S mode uses the computers and computer communication network to complete the all process of international trade business, including the contact with the customer and the signing of the contract; the choosing of supplier and the goods into the warehouse; payment to shipment of goods and etc., which are to transfer and import the international trade business of each process into computer information.

In this way, it not only can greatly save the time which is required to complete a business, and can also provide the macroscopic or microcosmic information, which lays a foundation for the information management of the company.

The goal of international trade information management system

This system has four objectives which are described as follows:

1) To establish the international trade business information management system, making the international trade enterprises to realize strategy transformation.

2) To establish international trade risk management information system, which is used to unify corporate customers and products resource management in order to establish a complete customer credit evaluation and risk prevention system.

3) Cash flow and cost control. [1]The international trade information management system, like the management mechanism, can provide prior budget to control the cost during the things and settle accounts later.

4) The decisions support the establishment of the system. International trade management system can dynamically at any time provide the necessary information for decision making process, and data support and scheme selection. And it can also give performance feedback to the decision-makers in order to adjust the decision.

\section{The international trade information management system based on $\mathrm{B} / \mathrm{S}$}

\section{Structure analysis of the system}

The design of the system overall adopts the more advanced multi-layer architecture of B/S mode, the concrete of which can be divided into the presentation layer, the Web server, application server layer and data layer, as shown in chart 1. 


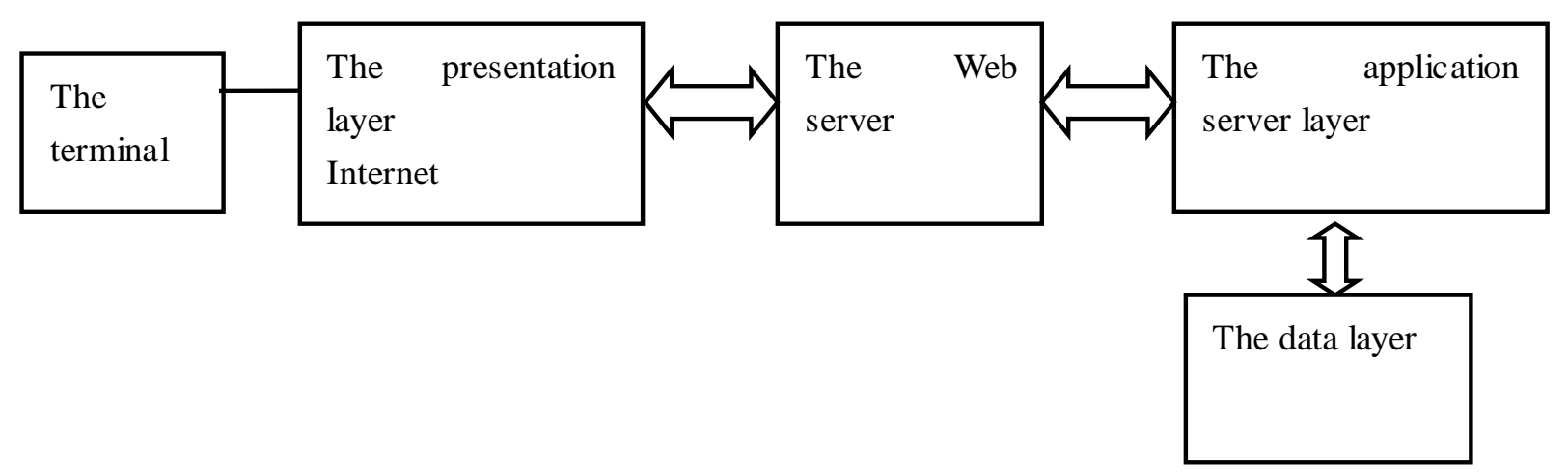

Chart 1: Structure of B/S model

From the chart 1,we can see that when the customer need the services of the server, so that needs an HTML page, uses browser as a starting point, sends out demands through the form or other way, receives and analyzes the form using the Web server,. And if it is the general URL request, it will be directly handled and sends service in the Web server. If there are specific requirements such as to get access, query the content of the back-end database, which are dealt by the relevant processing program through the database engine or ODBC, and then get access to it, and dealt the demands with the Database or the server. It will turn back the results in order to respond to a Web server and the client browser. [2] These results will be performed by the browser to explain the results and display the results.

The different functions of the four layers are described as following:

(1) The presentation layer, managing the interface section of users in the system, namely the man-machine interface, which is used to collect information users input and give feedback the result.

(2) The web server layer mainly is the WEB server. The function of the system mainly includes two aspects: one is responsible for receiving the user's application, dealing with the request of the client (Browser), calling in the corresponding business object on application Server, completing the information query and modify; second is to receive the result returning to the application, which shows in the Browser screen in the form of a Web page.

(3) The application server layer mainly is responsible for completing system application and business logic, such as validation data validity, data processing and data exchange layer etc.

(4) The data layer is made up of the database server, mainly responsible for operation and maintenance of the database of international trade management system, move quickly to implement a large amount of data retrieval and update.

\section{Module and function design of international trade information management system}

Shown in following chart 2 and 3, the system is divided into seven modules, respectively the export management module, supplier management module, inventory management module, transportation management module, document management module, data management module and managers management module.

(1) The export management module includes submodules of export contract, registration of exchange, sales process and export audit, its main function is after logging in the sales contract, on the basis of the contract, tracking the $\mathrm{L} / \mathrm{C}$ and relevant documents or the key link in the process of fulfilling the contract[3].

(2) The supplier management module includes submodules of purchasing contracts, purchasing, purchasing plan, purchasing process and delivery plan, its function is to be able to help procurement staff control and complete the purchase plan.

(3) The inventory management module includes receipt and warehousing plan list submodules, its function is to help the warehouse staff operate comprehensive control and management of the inventory items of inbound and outbound operations.

(4) The transportation management module includes submodules of registration of shipment, packing, transportation planning and packing measurement; its function is to provide such 
management functions of order registration of shipment, packing and other management functions.

(5) The documents management module is used to modify, query, print and send various documents involving in the process of import and export of goods.

(6) The data management module is to maintain and manage the relevant submodules of the commodity information, customer information, supplier information, in which users can quickly find the relevant information you need.

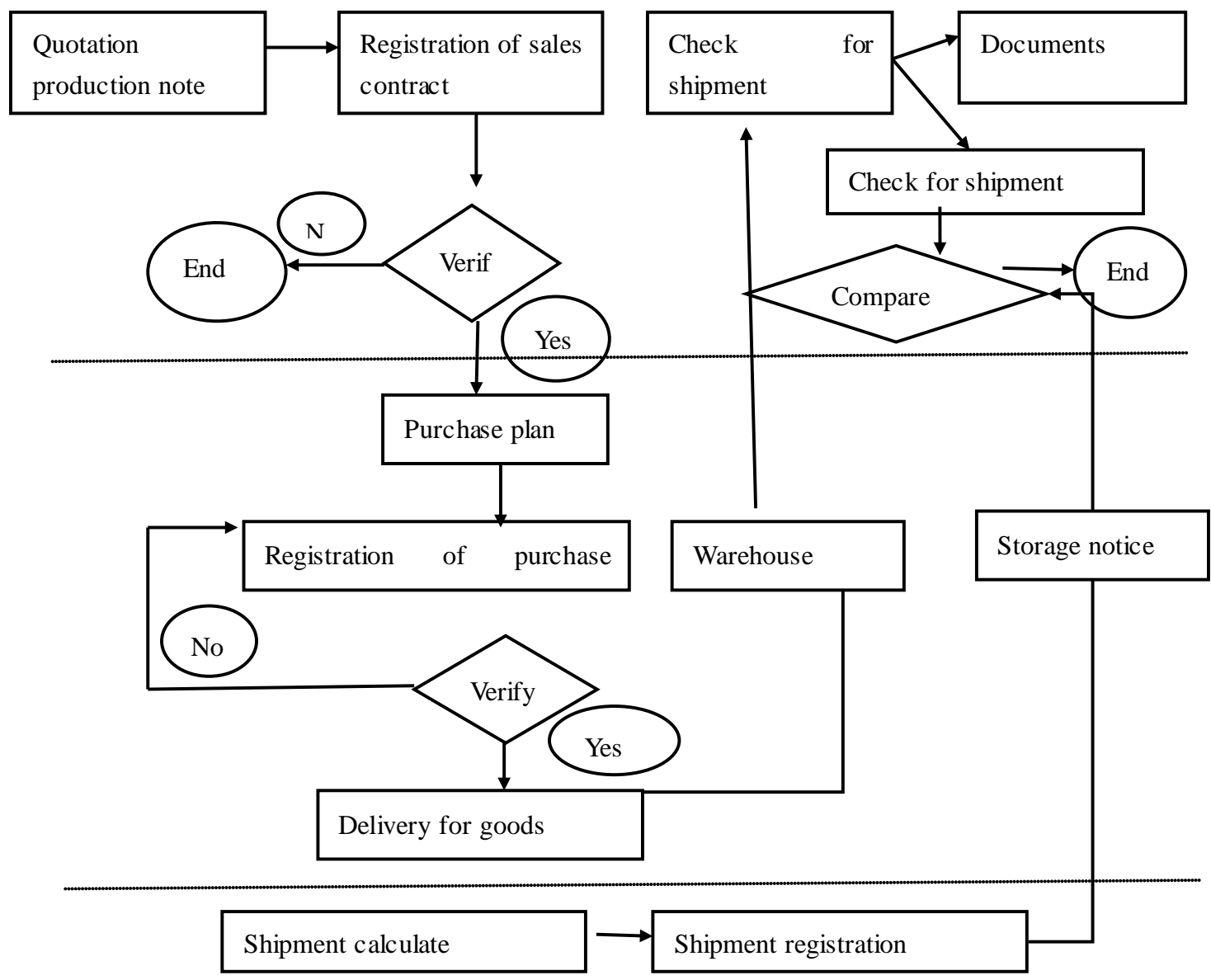

Chart 2: system implementation work flow chart

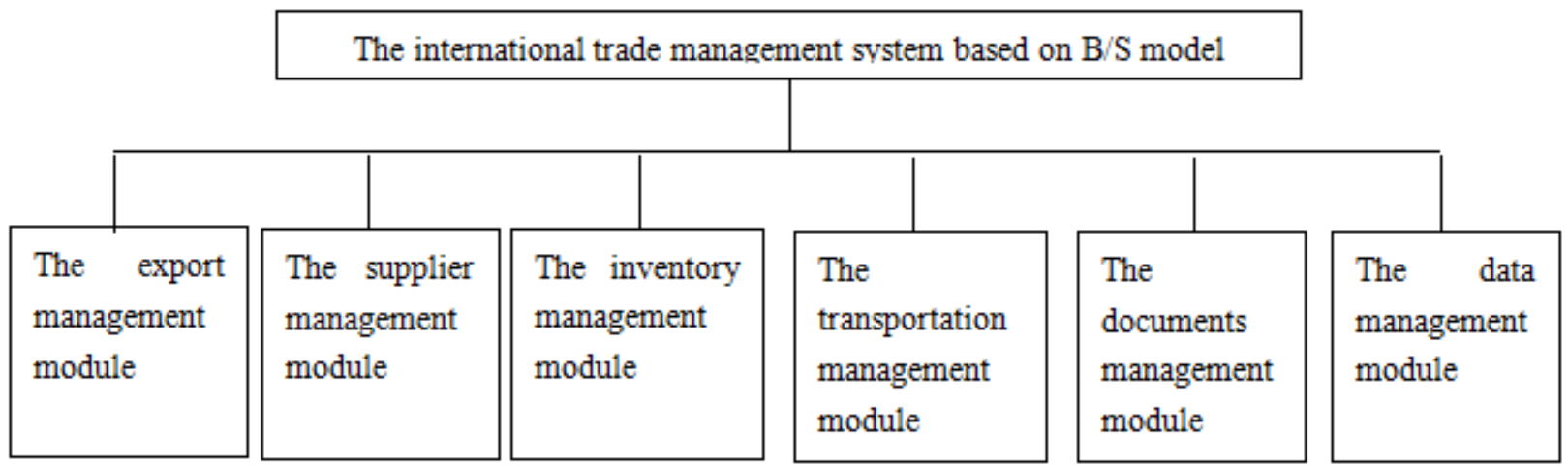

Chart 3: the structure of the system

\section{Key technologies in the design of the system.}

\section{NET technology in the design of four layer architecture}

Net Framework is a new platform of Microsoft designed for the development of application program. The NET has a very high affinity with the Web service. Saw from the distributed application system, a WEB project should have the functions of interact with the users, and deal 
with specific business and retain its status in the storage medium, which means it should have at least three layers: the presentation layer, business logic layer and data layer, so that software is of transparency and encapsulation, high cohesion and low coupling, easy to extend and maintenance.[4] Developers tend to division of labor and improve the development efficiency.

The system adopts four layers architecture based on ASP.NET development. Its basic content is to combine the object-oriented UML modeling with the Web application system development. The whole system is divided into four layers: the Web layer, suitable for the ASP.NET way of development; business entity layer; data access layer and business rule layer. On this way, the Web application not only reached the targets of code structure clear, high reusability, applicability, easy maintenance and transplant and it also can improve the speed of development of Web application system[5].

\section{Security mechanism}

Security is an important and necessary aspect for any management information system. In the international trade management system, system security includes two aspects: (1) the operation of inside the enterprise to the system needs to be done in their jurisdictions; (2) the server application program should take measures to prevent the malicious attacks. When logging in, the system will set corresponding interface and operating function according to different users. For the latter, in addition to using firewalls and other network security products, it also adopts the authentication mechanism and encryption technology in the application program. Without passing the authentication, when users visit the resource in Public PUM, they will be redirected to the login page, which reaches the purpose of protection of WEB resources. In addition, the encryption used in the security mechanism, such as encrypting important data, the receiver decryption after use, can prevent information forge and eavesdropping.

\section{Summary}

International trade enterprises urgently need to develop the international trade management system based on B/S mode in order to adapt to the current international trade development environment, provide better and higher quality of service, and strengthen the control of risk of the enterprise. And it also provides quick and effective management platform for the company for tracking the whole process of business to make comprehensive management of internal procurement, inventory, and sales of international trade company possible.

\section{References}

[1] Zhipign Jia, Xiuguo Wu, Hong Pei, The MIS structure Analysis of Company Based On bind of C/S And B/S Mode[J]. Microcomputer Development, 2001, 11(3):17-19.

[2] Xianghong Li, Xiaomei Chu, The Application Development of Web Based on Internet[J]. Microcomputer Development, 2002, 12(1):53-57.

[3] Zhen Jia, Introduction to E-Commerce[M]. Posts and Telecom Press,2000,79-81.

[4] Liu Qiao ling, Nanjing Audit Institute, Nanjing 210029, China, Research of Development of Commerce Information Management System of International Trade Based on B / S, 2003, 51-54.

[5] Xiaobao Hou, Chen Zheng, Water Resource and Power, Design and Realization of Management Information System for International Trade Based on B / S Mode[J].2007, 94-99. 